\title{
Effect of preoperative exposure to salty food on food selection in adrenalectomized rats
}

\author{
DOUGLAS L. GRIMSLEY \\ University of North Carolina at Charlotte, Charlotte, North Carolina
}

\begin{abstract}
Rats that have been adrenalectomized will seek $\mathrm{NaCl}$ in food or in a solution, but they show a marked preference to regulate salt balance by drinking rather than eating. The hypothesis that rats do not regulate $\mathrm{NaCl}$ by eating because of limited exposure to diets rich in $\mathrm{NaCl}$ was tested in the present experiment. Twenty weanling rats were divided into two major groups: (1) experienced animals who were fed lab chow with extra $\mathrm{NaCl}$ added for 40 preoperative days, and (2) inexperienced animals that ate plain lab chow preoperatively. Half of each of these groups were adrenalectomized and half were sham operated. All animals had access to both plain and $\mathrm{NaCl}$-nriched food postoperatively. The results showed that the adrenalectomized rats consumed considerably more $\mathrm{NaCl}$-enriched food than did the sham animals, but that preoperative salt experience had no significant effect on intake. Sodium-deficient rats will seek out $\mathrm{NaCl}$ in food and regulate their salt need; this behavior occurs with or without preoperative experience with $\mathrm{NaCl}$ enriched foods.
\end{abstract}

It is well established that rats will increase their intake of salt following bilateral adrenalectomy. The salt preference will emerge in spite of conditioning a preoperative aversion to such substances (Frumkin, 1971), associating salt consumption with irradiation (Cullen, 1969), or establishing preferences for highly palatable solutions (Grimsley, 1970; Grimsley \& Cullen, 1968; Grimsley \& Fisher, 1967).

It is not clear, however, that rats are motivated to seek salt in food and in solution equally. Fregly, Harper, and Radford (1965) varied the salt content of food while offering distilled water and a salt solution to salt-deprived rats. Changes in salt levels in the food failed to influence intake, even when the salt concentration in the food reached $6 \%$. Grimsley (1973) showed that adrenalectomized (ADX) rats would consume enough of a salt-enriched food to maintain body weight and to prevent the symptoms characterisitic of adrenal insufficiency. But given a choice between salt in food and in solution, the ADX animals showed a marked preference to regulate salt balance by drinking (Grimsley \& Starnes, 1979).

Ordinarily, rats without a salt deficiency will not prefer a salty food over a plain food. This has been shown with lab chow (Grimsley, 1973), and with a variety of other foods, including potato chips, peanuts, and soup (Beauchamp \& Bertino, 1985). The preference for plain food over the same food salted can be reversed by a number of treatments, including feeding the rats a sodiumdeficient diet (Rogers, 1967), administering the drug

This work was supported in part by funds from the Foundation of The University of North Carolina at Charlotte and from the State of North Carolina. Address all correspondence to Douglas L. Grimsley, Department of Psychology, University of North Carolina at Charlotte, Charlotte, NC 28223. furosemide (Bertino \& Tordoff, 1988), and adrenalectomy (Grimsley, 1973).

Beauchamp and Bertino (1985) and others have suggested that rats do not regulate salt by eating, because they have limited exposure or a lack of exposure to diets rich in salt. Human beings, on the other hand, receive extensive exposure to highly salty foods from an early age, and perhaps this partly explains the preference for salt regulation by means of eating food in human beings, as opposed to drinking in rats.

The present study was designed for examination of the issue of whether prolonged exposure to an $\mathrm{NaCl}$-enriched diet would modify the salt-seeking behavior of adrenalectomized rats.

\section{METHOD}

\section{Subjects and Apparatus}

Twenty male Sprague-Dawley rats, averaging $55 \mathrm{~g}$ at the start of the experiment, were obtained as weanlings and housed individually. They ate from two glass cups attached to the front of each cage, with a drinking tube in between.

\section{Procedure}

Upon arrival, 10 of the animals were randomly selected to serve as the $\mathrm{NaCl}$ experienced group. During the first 38 preoperative days, they were fed only $\mathrm{NaCl}$-enriched lab chow, which consisted of ground Purina Lab Chow with salt added: $3 \mathrm{~g}$ of $\mathrm{NaCl}$ added per $100 \mathrm{~g}$ of food, thoroughly mixed. The other 10 animals (the inexperienced group) received only plain lab chow in the two cups for the 38 preoperative days. Both groups then received both plain and $\mathrm{NaCl}$-enriched foods for the last 2 preoperative days. The $\mathrm{NaCl}$ and plain food cups were alternated daily to control for position preferences. Body weights, water intake, and food consumption were measured at approximately 2 p.m. daily. The $12-\mathrm{h}$ period with lights on went from 8 a.m. to 8 p.m. followed by 12 h of darkness.

Surgery was performed under aseptic conditions, with the use of ether anesthesia. A dorsal approach exposed the adrenal glands. 
All the animals were kept warm and under observation until they had fully recovered from the anesthesia.

Six of the 10 experienced animals were randomly assigned to the ADX group and received bilateral adrenalectomy. The remaining 4 animals received sham surgery, consisting of bilateral exposure of the adrenals without removal. Similarly, 6 of the inexperienced animals were adrenalectomized, and 4 received sham surgery. All the animals were then given a choice between plain food and $3 \%$ $\mathrm{NaCl}$-enriched food for 17 days. On Day 18, the amount of $\mathrm{NaCl}$ added to the food was raised to $6 \%$ for 8 days, and then returned to $3 \%$ for 7 additional days.

\section{RESULTS}

One of the animals in the ADX experienced group died during surgery, so the data for that group is based on 5 animals. All of the graphs were plotted beginning with the mean of preoperative Days 39 and 40 (PRE). Postoperative plots show the means of 2-day intervals, except on Days 17 and 32, which show the group means for those days only.

An analysis of food intake during the second half of the preoperative period, which comprised Days 20-38, after the animals had adjusted to the food cups and routine but before both foods were provided, showed no significant differences between groups $(p>.05)$. There was a significant effect of days $[F(18,270)=4.87, p<.01]$, showing an increase in the amount eaten by the groups over days. Analysis of total food intake for Days 39 and 40 , when both types of food were available, revealed no significant differences among the groups $(p>.05)$.

Further analysis of the last 2 preoperative days showed that all groups preferred the plain food. The intake of plain food was particularly high and the intake of $\mathrm{NaCl}$-enriched food low for both experienced groups on Day 39 of the preoperative period, the first day in which plain food was available to these groups. The differences between groups in plain-food intake for preoperative Days 39 and 40 were statistically significant $[F(3,15)=4.06, p<.05]$. The days effect was also significant $[F(1,15)=8.23, p<$ .01 ], and there was a significant interaction effect between days and groups $[F(3,15)=8.17, p<.01]$, for the experienced animals reduced their intake of plain food and increased their intake of $\mathrm{NaCl}$-enriched food on Day 40.

Water intake was high for the experienced animals on Days $20-38$ preoperatively $[F(3,270)=40.87, p<.01]$, due to the high salt content of the food. There was also a significant increase over Days 20-38 $[F(18,270)=9.29$, $p<.01]$. No difference in water intake was found between the groups on Days 39 and 40 preoperatively.

The percentage of the total food intake that consisted of $\mathrm{NaCl}$-enriched food is shown in Figure 1, for each concentration. It can be seen that for the ADX animals, most intake was chosen from salt-enriched food. For example, during the first 17 days postop, when the salty food was $3 \% \mathrm{NaCl}$-enriched, the ADX animals increased their intake steadily and consumed approximately $80 \%-90 \%$ of total intake as salty food by Day 17 . When the amount of salt added was increased to $6 \%$, the percentage of $\mathrm{NaCl}$-enriched food intake fell immediately to $50 \%-60 \%$

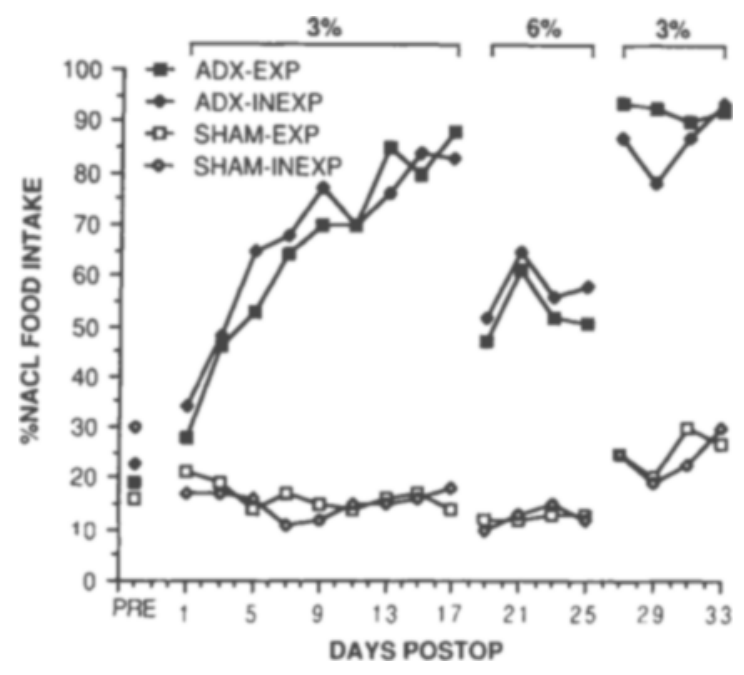

Figure 1. Salty food intake as a percentage of total food intake, for the last 2 preoperative and the 32 postoperative days.

and then returned rapidly to approximately $90 \%$ when the amount of added $\mathrm{NaCl}$ in the food was returned to $3 \%$. Experienced and inexperienced animals consumed similar amounts of $\mathrm{NaCl}$-enriched food, and no significant differences were found $(p>.05)$.

After adrenalectomy, both of the ADX groups showed an immediate and sustained increase in intake of $\mathrm{NaCl}$ enriched food, as shown in Figure 2. During the first 17 days, they selected significantly more $\mathrm{NaCl}$-enriched food than plain food $[F(3,240)=32.99, p<.01]$. There was also a significant effect of days $[F(16,240)=15.30, p<$ $.01]$. The groups $\times$ days interaction was significant $[F(48,240)=5.01, p<.01]$, where only the ADX groups increased their intake.

The ADX animals continued to show significantly greater intake of $\mathrm{NaCl}$-enriched food than did the sham animals as the amount of added $\mathrm{NaCl}$ was raised to $6 \%$ $[F(3,105)=19.04, p<.01]$. There was also a signifi-

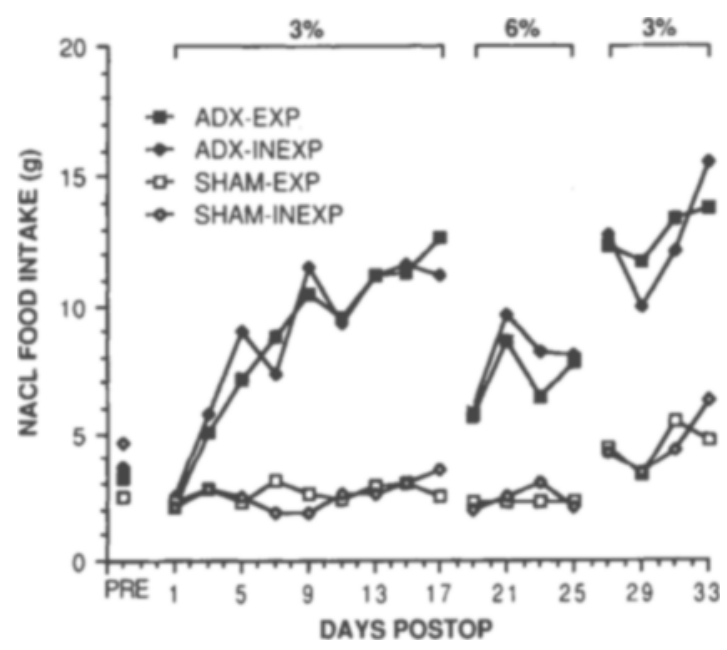

Figure 2. Mean $\mathrm{NaCl}$ food intake for the last 2 preoperative and the 32 postoperative days. 
cant effect of days $[F(7,105)=3.81, p<.01]$. When the percentage of $\mathrm{NaCl}$ added to the food was reduced to $3 \%$ (on Days 26-32), there continued to be a significant difference between the groups $[F(3,90)=24.29$, $p<.01]$, as well as a significant effect of days $[F(6,90)$ $=9.91, p<.01]$. The ADX groups were not significantly different from each other, nor were the sham groups significantly different from each other $(p>.05)$, with respect to any of the $\mathrm{NaCl}$-enriched food concentrations tested.

Following 8 days of experience with the $6 \% \mathrm{NaCl}-$ enriched food, there appears to have been an increased preference for the 3\% NaCl-enriched food, particularly for the sham groups. The intake data for $3 \% \mathrm{NaCl}$ enriched food for Days 14-17 was compared to the data for Days 29-32 for each group. No statistically significant differences were found.

The total food intake (plain $+\mathrm{NaCl}$-enriched) for Days 39 and 40 and for the postoperative period is shown in Figure 3. There is a significant groups $[F(3,240)=10.71$, $p<.01]$ and days $[F(16,240)=17.84, p<.01]$ effect for Days 1-17. The groups are also significantly different during Days $18-25[F(3,105)=6.62, p<.01]$. The differences between groups are not significant for Days 26-32 $(p>.05)$, though there is a significant days effect $[F(6,90)=9.96, p<.01]$.

Analysis of the data concerning plain food intake showed that the sham animals consumed significantly more plain food than did the ADX animals during Days $1-17$ postop $[F(3,240)=62.99, p<.01]$. There was also a significant days effect $[F(16,240)=3.72, p<$ $.01]$. The significant groups $\times$ days interaction $[F(48,240)$ $=5.44, p<.01]$ occurred as the ADX animals gradually decreased their intake while the sham animals increased theirs. Both the ADX and the sham animals showed an increase in plain-food consumption when $6 \%$ $\mathrm{NaCl}$-enriched food was used, and the significant difference between the groups continued $[F(3,105)=44.23$,

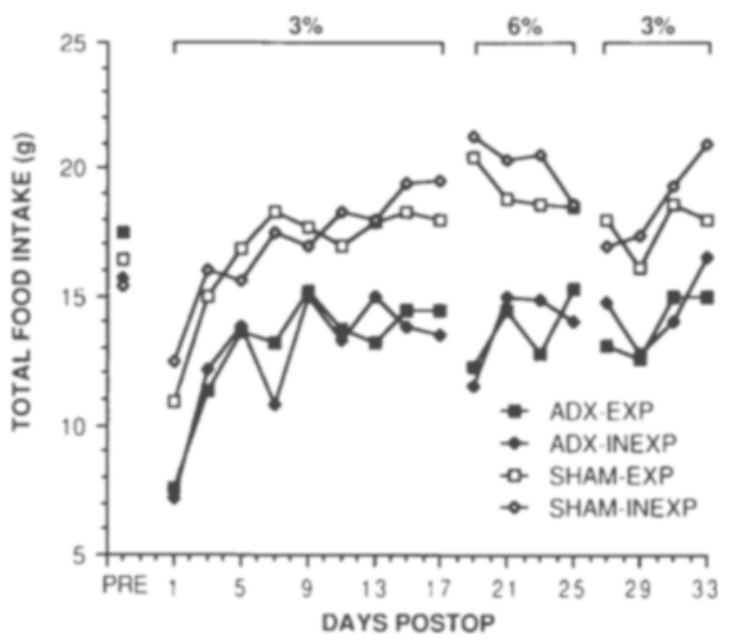

Figure 3. Total food intake for the last 2 preoperative and the 32 postoperative days.

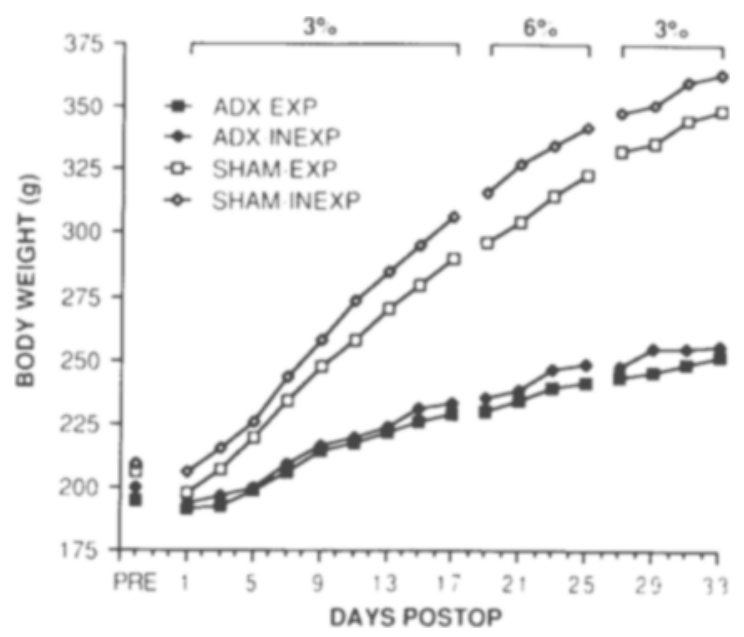

Figure 4. Mean body weight for the last 2 preoperative and the 32 postoperative days.

$p<.01]$. There was also a significant difference among the groups $[F(3,90)=53.56, p<.01]$, as well as a significant days effect $[F(6,90)=2.35, p<.05]$. The marginally significant groups $\times$ days interaction $[F(18,90)$ $=1.80, p<.05$ ] during the last 7 days of measurement, when the $\mathrm{NaCl}$-enriched food was again reduced to $3 \%$, occurred in conjunction with the continuing gradual decline in plain-food consumption by ADX animals and the continuing slight increase in consumption by sham animals. Neither the two ADX groups nor the two sham groups were significantly different from each other.

All of the animals showed an increase in body weight (see Figure 4 ) over the 32 postoperative days, though the ADX animals remained significantly lighter throughout. The differences between groups $[F(3,240)=15.84$, $F(3,105)=32.36$, and $F(3,90)=35.09]$ and days $[F(16,240)=360.23, F(7,105)=91.38$, and $F(6,90)=$ $53.10]$, and the groups $\times$ days interaction $[F(48,240)=$ $21.30, F(21,105)=4.02$, and $F(18,90)=3.81]$, for the $3 \%, 6 \%$, and $3 \%$ periods, respectively, were all significant $(p<.01)$. All of the ADX animals survived the postoperative period. Water intake was similar for all groups during the course of the postoperative period, and there were no statistically significant differences $(p>.05)$.

\section{DISCUSSION}

Exposure to only $\mathrm{NaCl}$-enriched food over a 38 -day period failed to alter the consumption of plain and $\mathrm{NaCl}$ enriched food for the ADX rats. The lengthy exposure to salty food did not enhance or diminish their consumption of the $\mathrm{NaCl}$ needed to correct the deficiency created by the surgery. The experienced and inexperienced ADX animals were similar in their amounts and patterns of consumption of plain and $\mathrm{NaCl}$-enriched food following adrenalectomy. Likewise, for the sham animals, prolonged exposure to $\mathrm{NaCl}$-enriched food did not lead to 
permanent changes in their pattern of food intake. The sham experienced animals, like their inexperienced counterparts, consumed large amounts of plain food and little $\mathrm{NaCl}$-enriched food, as soon as plain food was available to them.

It is interesting that the intake of $3 \% \mathrm{NaCl}$-enriched food was greater after experience with the $6 \% \mathrm{NaCl}$-enriched food (Days 26-32), even though the increase was not statistically significant (see Figure 2). The greatest increase occurred in the two inexperienced groups. Whether this increase is a transient contrast effect or a specific effect of experience cannot be answered easily from the present data. Although it is clear that for drinking behavior, experience with different concentrations of $\mathrm{NaCl}$ solutions can change preferences (Theios, Derivera, \& Aronson, 1962), a similar effect for eating behavior has not been clearly demonstrated.

Rats, given a choice between a variety of foods offered plain or with added salt, usually show a preference for the plain food (Beauchamp \& Bertino, 1985). Even when offered a variety of concentrations, rats do not prefer salted food. In an attempt to modify their preference behavior, Beauchamp and Bertino exposed rats for varying periods of time to salted and unsalted potato chips. Even after 14 weeks of exposure, the rats preferred unsalted chips, and there was no statistically significant difference between experienced and inexperienced animals.

Although sodium-deficient rats may not prefer to regulate $\mathrm{NaCl}$ by eating food, nevertheless, $\mathrm{NaCl}$ appetite during a sodium-deficient state continues to be a powerful demonstration of specific hunger behavior in rats. Salt seeking will occur with whatever means is available, whether it be food or drink, and long experience with salty food is not a prerequisite for this behavior to occur.

The results obtained in this study are consistent with a growing body of literature, which shows that rats will meet their needs and will switch choices in spite of established preferences. Bronson (1966) showed that adult rats do not necessarily prefer the type of solid food they were first fed in infancy. Established preferences for sucrose or saccharin will not be maintained in the presence of a salt need created by adrenalectomy (Grimsley, 1970; Grimsley \& Cullen, 1968; Grimsley \& Fisher, 1967).

It is not possible to tell from the present data whether the regulation of $\mathrm{NaCl}$ intake is due primarily to taste or to postingestional factors, since the adrenalectomized animals had unlimited access to $\mathrm{NaCl}$-enriched food. Wolf, Schulkin, and Simson (1984) have suggested the likelihood of multiple factors involved in the regulation of salt intake in rats, since the full effect of salt-intake adjustments may take as long as $16 \mathrm{~h}$ to occur when stomach loading is used. On the other hand, Rabe and Corbit (1973) showed that postingestional factors alone are sufficient to produce the normally found preferenceaversion for $\mathrm{NaCl}$ solutions of different concentrations.
The present study shows that sodium-deficient rats will seek out $\mathrm{NaCl}$ in food and regulate their salt need, and that the preference for $\mathrm{NaCl}$-enriched food following ADX occurs with or without the preoperative experience with $\mathrm{NaCl}$-enriched foods. Since the experienced and inexperienced rats exhibited similar $\mathrm{NaCl}$-enriched food intakes, there appears to be no necessary role for prior experience with salty food in this salt-seeking behavior. Adrenalectomy will produce $\mathrm{NaCl}$-seeking behavior. While the deficient rats may prefer to regulate their salt balance by means of the intake of salt in solution (Grimsley \& Stames, 1979), they are clearly able to regulate their salt balance by means of the intake of $\mathrm{NaCl}$ in food.

\section{REFERENCES}

Beauchamp, G. K., Bertino, M. (1985). Rats (Rattus norvegicus) do not prefer salted solid food. Journal of Comparative Psychology, 99, 240-247.

Bertino, M., \& ToRdoff, M. G. (1988). Sodium depletion increases rats' preferences for salted food. Behavioral Neuroscience, 102 , 565-573.

Bronson, G. (1966). Evidence of the lack of influence of early diet on adult food preferences in rats. Journal of Comparative \& Physiological Psychology, 62, 162-164.

Cullen, J. W. (1969). Modification of salt-seeking behavior in the adrenalectomized rat via gamma-ray irradiation. Joumal of Comparative \& Physiological Psychology, 68, 524-529.

Fregly, M. J., Harper, J. M., JR., RAdFord, E. P., JR. (1965). Regulation of sodium chloride intake by rats. American Journal of Physiology, 209, 287-292.

FrUMKIN, K. (1971). Interaction of $\mathrm{LiCl}$ aversion and sodium-specific hunger in the adrenalectomized rat. Journal of Comparative \& Physiological Psychology, 75, 32-40.

GrimsLeY, D. L. (1970). Salt seeking in the adrenalectomized rat with an established sugar preference. Journal of Comparative \& Physiological Psychology, 71, 384-389.

Grimsley, D. L. (1973). Salt seeking by food selection in adrenalectomized rats. Journal of Comparative \& Physiological Psychology, 82, $261-267$.

Grimsley, D. L., Cullen, J. W. (1968). Preoperative experience and postoperative fluid preference in adrenalectomized rats. Psychonomic Science, 12, 119-120.

Grimsley, D. L., \& Fisher, L. E., JR. (1967). Preoperative saccharine experience and postoperative fluid preference in adrenalectomized rats. Psychonomic Science, 9, 299-300.

Grimsley, D. L., \& Starnes, E. C. (1979). Salt seeking by means of food and fluid selection in adrenalectomized rats. Physiological Psychology, 7, 295-298.

Rabe, E. F., \& Corbit, J. D. (1973). Postingestional control of sodium chloride solution drinking in the rat. Journal of Comparative \& Physiological Psychology, 84, 268-274.

Rogers, W. L. (1967). Specificity of specific hungers. Journal of Comparative \& Physiological Psychology, 64, 49-58.

Theios, J., Derivera, J., \& Aronson, E. (1962). Modification of the rat's saline intake gradient by experience with specific concentrations. Psychological Reports, 10, 487-490.

Wolf, G., Schulkin, J., \& Simson, P. E. (1984). Multiple factors in the satiation of salt appetite. Behavioral Neuroscience, 98, 661-673.

(Manuscript received November 10, 1988; revision accepted for publication March 12, 1989.) 